\section{Manganese Provision in Parenteral Nutrition: An Update}

Nutrition in Clinical Practice

Volume XX Number X

Month 201X 1-14

C 2017 American Society

for Parenteral and Enteral Nutrition DOI: $10.1177 / 0884533617702837$ journals.sagepub.com/home/ncp

\author{
Callum Livingstone, FRCPath ${ }^{1,2}$
}

(S)AGE

\begin{abstract}
Manganese $(\mathrm{Mn})$ is an essential micronutrient required for the activity of metalloenzymes. It is an essential component of parenteral nutrition $(\mathrm{PN})$, but requirements are low. Mn status is difficult to assess, with the commonest method being measurement of its concentration in whole blood. This method has limitations, including artifactually high concentrations resulting from contamination of specimen tubes. Mn toxicity is a well-recognized complication of PN, the risk of which increases if there is cholestasis or if the patient has received high doses. It usually presents with parkinsonian-like symptoms but may be detected presymptomatically as hypermanganesemia or as increased signal intensity of the basal ganglia upon T1-weighted magnetic resonance imaging. Caution is necessary when providing Mn for patients on long-term PN (>1 month). It is advisable to withhold supplementation if hypermanganesemia or cholestasis develops. Deficiency of $\mathrm{Mn}$ is rare in patients treated with PN. PN regimens are contaminated with Mn in amounts likely to meet requirements. Consequently, it is debated whether PN should be routinely supplemented with Mn. The currently recommended dose of Mn in adults treated with PN is 55 $\mu \mathrm{g} / \mathrm{d}$, but the doses provided by most currently available multi-trace element products exceed this. In response to calls for new products to be developed, 2 new multi-trace element products are currently available in Europe that provide Mn doses of $55 \mu \mathrm{g} / \mathrm{d}$. Once these products are in general use, it is likely that the incidence of Mn toxicity will decrease. (Nutr Clin Pract. XXXX;xx:xx-xx)
\end{abstract}

\title{
Keywords
}

managanese; manganese toxicity; manganese deficiency; parenteral nutrition; selenium; iron

The trace element (TE) manganese ( $\mathrm{Mn})$ is an essential dietary component because it is required for the activity of numerous metalloenzymes. These participate in physiologic processes, including energy metabolism, antioxidant defense, tissue maintenance, wound healing, and functioning of the central nervous and immune systems. ${ }^{1}$ In health, homeostatic mechanisms prevent Mn deficiency or accumulation. However, in patients treated with parenteral nutrition $(\mathrm{PN})$, the intravenous (IV) delivery of $\mathrm{Mn}$ increases its bioavailability to $100 \%$. If provision of $\mathrm{Mn}$ exceeds the capacity for excretion, positive balance occurs, eventually leading to toxicity.

It is appropriate to review this subject at the present time because recent developments have important implications for clinical practice. First, there has been considerable progress in the understanding of Mn toxicity. Second, studies have suggested that underprovision of $\mathrm{Mn}$ has adverse effects. Finally, new multi-TE (MTE) products have been developed that contain Mn doses in line with the 2012 American Society for Parenteral and Enteral Nutrition (ASPEN) recommendations on TE provision in $\mathrm{PN}$. This article begins by covering the physiology of Mn and then provides an overview of Mn toxicity and deficiency, focusing on the findings of recent studies. The implications of these findings for patients treated with PN are considered. Finally, the article considers practical aspects of the provision of $\mathrm{Mn}$ in $\mathrm{PN}$.

\section{Physiology}

$\mathrm{Mn}$ is the 12th-most abundant element in the earth's crust, ubiquitously present in food and water supply. ${ }^{2}$ It exists in 11 oxidation states, of which $\mathrm{Mn}^{2+}$ and $\mathrm{Mn}^{3+}$ are the commonest in biological systems. The total Mn content of the human body is about $15 \mathrm{mg}$, the highest concentrations being in liver, kidney, and bone. ${ }^{3}$ Most of the Mn in tissues is located in mitochondria. ${ }^{4} \mathrm{Mn}$ metalloenzymes participate in the metabolism of amino acids, carbohydrates, and lipids. They include arginase, glutamine synthase, mitochondrial Mn superoxide dismutase (MnSOD), and 3-hydroxy-3-methylglutaryl-coenzyme A (HMG CoA) reductase, the rate-limiting enzyme in cholesterol biosynthesis. $\mathrm{Mn}$ is required for the activity of glycosyltransferases needed for formation of connective tissue. It is further required for synthesis and secretion of insulin, ${ }^{5}$ and it upregulates insulin-like growth factor I. ${ }^{6}$ As such, Mn is necessary for anabolism. It is essential for normal development and maintenance of bone. ${ }^{7}$

Under normal circumstances, exposure to $\mathrm{Mn}$ is mainly from food. Mn is naturally abundant in grains, nuts, fruits, and

From the ${ }^{1}$ Clinical Biochemistry Department, Royal Surrey County Hospital, NHS Foundation Trust, Guildford, UK; and the ${ }^{2}$ Faculty of Health and Medical Sciences, University of Surrey, Guildford, UK.

Financial disclosure None declared.

Conflicts of interest None declared.

Corresponding Author:

Callum Livingstone, FRCPath, Clinical Biochemistry Department, Royal Surrey County Hospital, NHS Foundation Trust, Guildford, Surrey GU2 $7 X X$, UK.

Email: callum.livingstone@nhs.net 
vegetables. Nuts, for example, contain up to $46 \mathrm{mg} / \mathrm{kg}$. ${ }^{8}$ Tea is a rich source of $\mathrm{Mn}$, containing $0.4-1.3 \mathrm{mg}$ in an average cup. The Mn content of milk varies widely, ranging from $3.5-15 \mu \mathrm{g} / \mathrm{L}$ in human milk $^{8}$ to approximately $300 \mu \mathrm{g} / \mathrm{L}$ in commercial infant formulas. ${ }^{9} \mathrm{Mn}$ intake from water is usually considerably lower than that from food. The Mn concentration of drinking water varies widely among sources, but at the median Mn concentration of $10 \mu \mathrm{g} / \mathrm{L}$, daily intake is likely to be about $20 \mu \mathrm{g}$. The U.S. Environmental Protection Agency has recommended that $\mathrm{Mn}$ concentrations in drinking water not exceed $50 \mu \mathrm{g} / \mathrm{L}$ and has stated a lifetime health advisory value of $300 \mu \mathrm{g} / \mathrm{L} .{ }^{10}$ Small amounts of $\mathrm{Mn}$ are inhaled, with the ambient concentration in urban air being about $40 \mathrm{ng} / \mathrm{m}^{3} .{ }^{10} \mathrm{Mn}$ reaches air as a result of industrial activities, including steel production and its use in the gasoline additive methylcyclopentadienyl Mn tricarbonyl.

Dietary $\mathrm{Mn}$ is absorbed in the proximal small bowel by the divalent metal transporter 1, also known as SLC11A2. The proportion of dietary $\mathrm{Mn}$ absorbed is small, reflecting low requirements. Only about $3 \%$ is absorbed from a typical diet containing 3-4 mg/d. ${ }^{11}$ After reaching the liver in portal blood, it is exported to tissues. About $60 \%-80 \%$ of $\mathrm{Mn}$ in blood is located inside red blood cells (RBCs). ${ }^{12}$ In blood plasma, $\mathrm{Mn}$ is bound to albumin $(84 \%)$, hydrated $(6.4 \%)$, or complexed to bicarbonate and citrate ions. ${ }^{13,14}$ Before it can enter tissues, it is oxidized to $\mathrm{Mn}^{3+}$ by ceruloplasmin, enabling it to bind to transferrin. Transferrin binds to the transferrin receptor, which is endocytosed. Transport of Mn into cells occurs via divalent metal transporter 1 and ZIP8, an electroneutral influx symporter. Mn efflux from cells is mediated by 3 transportersnamely, SLC30A10, ferroportin, and the P-type ATPase secretory pathway Ca-ATPase 1 (SPCA1). ${ }^{14,15}$ SLC30A10 is a solute carrier abundant in liver, and it appears to protect cells against excessive accumulation of $\mathrm{Mn}$. The roles of the other 2 transporters in maintaining Mn balance are less clear. Excretion of $\mathrm{Mn}$ from the body occurs largely in bile (90\%), ${ }^{16}$ with the remainder being excreted in urine. Homeostasis of $\mathrm{Mn}$ is achieved mainly by regulation of biliary excretion. Normal hepatic function is therefore vital for $\mathrm{Mn}$ homeostasis. Intestinal absorption of $\mathrm{Mn}$ is subject to regulation, the percentage absorbed being inversely associated with the amount ingested. Mn absorption is influenced by iron (Fe) status, increasing when Fe stores are low and decreasing when dietary Fe is high. ${ }^{17,18} \mathrm{Fe}$ shares the same transport mechanisms as Mn.

\section{Mn and the Nervous System}

Mn metalloenzymes are necessary for normal functioning of the nervous system. The role of arginase in the brain is unclear, but there is evidence for neuroprotective effects. ${ }^{19}$ By hydrolyzing arginine, it may promote neuronal survival by decreasing nitric oxide synthesis. ${ }^{20}$ Glutamine synthase is the most abundant Mn metalloenzyme in mammalian brain, accounting for about $80 \%$ of brain $\mathrm{Mn}^{21}$ It is abundant in astrocytes, where it converts glutamate to glutamine for export to neurons and conversion back to the neurotransmitter glutamate. ${ }^{19}$ Uptake of glutamate by astrocytes depends on glutamine synthase activity. This activity prevents extracellular glutamate concentrations from climbing to toxic levels. In experimental systems lacking glutamine synthase, the ability of astrocytes to protect neurons from excitotoxicity is impaired. ${ }^{22}$ MnSOD clears superoxide radicals generated by aerobic metabolism in mitochondria. ${ }^{23}$ It catalyzes the dismutation of superoxide anions to hydrogen peroxide and oxygen, thereby protecting neurons against oxidative stress.

$\mathrm{Mn}$ is transported into the brain mainly across the bloodbrain barrier and choroid plexuses, but transport may occur via the olfactory nerve. ${ }^{13,14}$ Mn leaves the brain more slowly than it leaves other tissues. ${ }^{15}$ Kinetic studies suggest that this occurs by diffusion rather than being carrier mediated. ${ }^{24}$ Regulation of Mn influx and efflux is poorly understood, but studies of animals and cultured cells have investigated possible mechanisms. Briefly, Park9, also called ATP13A2, is believed to shuttle cations across lysosomal membranes and to protect against Mn accumulation when its expression is increased. ${ }^{25}$ SPCA1 is believed to be an important regulator of Mn in brain. It is thought that, when cytosolic Mn concentrations are excessive, $\mathrm{Mn}$ is pumped into the Golgi lumen through SPCA1 and subsequently excreted from cells. Expression of SPCA1 increases in brain mitochondria of animals chronically exposed to $\mathrm{Mn}$, and loss of function of SPCA1 increases sensitivity to Mn toxicity. ${ }^{26}$ The metal-binding protein metallothionein may have a role in detoxification of $\mathrm{Mn}$. Mn exposure decreases mRNA for metallothionein in cultured astrocytes and induces metallothionein in mouse liver in the presence of interleukin $6 .^{27,28}$ This subject has been discussed in detail elsewhere. ${ }^{19}$

\section{Assessment of Mn Status}

The method most commonly used to assess Mn status in patients is measurement of the whole blood Mn concentration. As a test of Mn status in patients treated with PN, it is considered superior to serum or plasma Mn. ${ }^{29-32}$ Whole blood Mn concentrations are affected by age, sex, and pregnancy. In neonates, concentrations are threefold higher than in adults. ${ }^{33}$ Concentrations are higher in women after puberty, possibly reflecting increased $\mathrm{Mn}$ absorption in response to lower $\mathrm{Fe}$ status. ${ }^{34}$ Concentrations increase in late pregnancy. ${ }^{33}$ For clinical purposes, Mn is usually measured either by atomic absorption spectroscopy ${ }^{35}$ or by inductively coupled plasma-atomic emission spectrometry. ${ }^{36}$

As a test of Mn status, whole blood Mn suffers from 2 notable limitations - namely, that biological variation is wide and measured concentrations may be artifactually high. ${ }^{37}$ Artifactual results may occur because $\mathrm{Mn}$, owing to its ubiquitous nature, tends to contaminate glassware, solutions, and specimen tubes. Mn concentrations cannot be reliably interpreted unless glassware has been acid-washed to minimize contamination. ${ }^{16}$ Researchers have considered whether the confounding effect of 
contamination can be avoided by measuring the more reliable serum copper $(\mathrm{Cu})$ as a surrogate test of $\mathrm{Mn}$ status. ${ }^{38}$ However, the serum $\mathrm{Cu}$ concentration did not correlate with whole blood $\mathrm{Mn}$, nor has measurement of Mn metalloenzymes in blood found a place in the assessment of Mn status. MnSOD of mononuclear cells has been investigated as a marker of tissue $\mathrm{Mn}$ status in animals but does not have clinical utility in humans. ${ }^{39}$ Blood arginase has been studied as a possible biomarker of $\mathrm{Mn}$ status but has not been adopted into clinical practice. ${ }^{40}$ Most studies that have reported on Mn deficiency or toxicity have measured whole blood $\mathrm{Mn}$, which, until tests for superior biomarkers are developed, is the test of choice.

Few studies have investigated the effect of the acute-phase response on tests of Mn status. One study of patients with chronic inflammation, caused by ankylosing spondylitis, reported that the serum concentration of Mn decreased along with those of $\mathrm{Fe}$ and zinc $(\mathrm{Zn}) .{ }^{41} \mathrm{~A}$ separate study of patients with hepatitis reported that serum Mn increased in patients with acute hepatitis as compared with controls but that RBC Mn remained unchanged. ${ }^{42}$ Whole blood Mn would be unlikely to have changed significantly given that most is located in RBCs. However, whole blood Mn was not measured directly. It is uncertain whether the findings of this study are applicable to other acute conditions.

\section{Mn Toxicity}

\section{Mn-Induced Neurotoxicity}

The earliest description of neurotoxic effects resulting from Mn toxicity was by Couper in 1837 among patients who had inhaled Mn oxide dust during the manufacture of bleach. ${ }^{43}$ Since 1967 it has been recognized that welders and miners are at risk of Mn toxicity. ${ }^{14,44}$ Workers in these occupations may be exposed to excessively high airborne $\mathrm{Mn}^{44}$ In welding workshops, for example, air Mn concentrations of $0.2 \mathrm{mg} / \mathrm{m}^{3}$ have been reported, considerably higher than in ambient urban air. ${ }^{45}$ While the amount of Mn inhaled by these workers is low versus oral intake, inhaled Mn predisposes to neurotoxicity because it reaches the brain directly via the olfactory nerve.

When $\mathrm{Mn}$ is present in excess, it accumulates in brain regions responsible for control of motor and nonmotor functions - namely, the globus pallidus, subthalamic nucleus, and substantia nigra. ${ }^{46}$ The globus pallidus appears to be particularly susceptible because there are abundant dopamine receptors that bind $\mathrm{Mn}$. Mn accumulation initially occurs asymptomatically. The patient later develops a parkinsonianlike syndrome consisting of tremor, hypertonia, bradykinesia, and gait disturbance, but nonspecific symptoms have been reported, including visual disturbance, headache, anxiety, memory loss, and seizures. ${ }^{47-49}$ The features are described as "parkinsonian-like" because they mimic, but are not identical to, those of Parkinson's disease (PD). Tremor is less frequent and hypertonia more frequent than in PD. ${ }^{46,50}$ Furthermore, PD tends to affect the striatum, and Lewy bodies (the histologic hallmark of PD) are absent in Mn toxicity. ${ }^{14} \mathrm{Mn}$ accumulation in brain can be assessed through T1-weighted magnetic resonance imaging (MRI) of the globus pallidus. A pallidal index is calculated by dividing the signal from the globus pallidus by the signal from frontal cortex white matter and multiplying by 100. In the context of occupational Mn exposure, the pallidal index is specific for Mn exposure during and even before clinical neurotoxicity develops. ${ }^{51}$ The pallidal signal disappears some months after cessation of exposure, irrespective of whether the Mn exposure is airborne or IV..$^{52,53}$

The mechanism whereby $\mathrm{Mn}$ causes neurotoxicity is unknown, but the hypothesis best supported by evidence is that it results in oxidative stress-induced damage to the dopaminergic system. ${ }^{54}$ Reactive oxygen species may be generated as a result of the pro-oxidant effect of Mn when present at high concentrations ${ }^{55}$ and by direct inhibition of cellular respiration, ${ }^{56}$ leading to progressive neuronal degeneration. There is further support for this hypothesis from observations that the antioxidant $\mathrm{N}$-acetylcysteine protects cells against toxicity ${ }^{57}$ and from evidence for oxidative damage in welders exposed to Mn occupationally. ${ }^{44}$ In studies of animals, Mn intoxication paradoxically decreases glutamine synthase activity in the basal ganglia. ${ }^{58} \mathrm{Mn}$ exposure decreases glutamate uptake by astrocytes. ${ }^{59}$ These effects would be expected to impair the ability of astrocytes to protect neurons from the toxic effects of excessive extracellular glutamate.

Mn-induced neurotoxicity and PN. Mn toxicity is a well-recognized complication of PN. It was first reported in 1990 in a 32-year-old woman with cholestatic jaundice who presented with parkinsonian-like symptoms and hypermanganesemia after receiving $\mathrm{Mn}$ doses of $300 \mu \mathrm{g} / \mathrm{d}$ for 4 months. ${ }^{29}$ The symptoms and hypermanganesemia resolved after supplemental Mn was withheld. Patients were later described in whom cerebral Mn accumulation was detected by MRI of the basal ganglia. ${ }^{60-62} \mathrm{Mn}$ accumulates in liver, but it remains unclear whether this is directly hepatotoxic. ${ }^{63}$

$\mathrm{Mn}$ is a ubiquitous contaminant of PN..$^{16,64}$ This raises safety concerns, especially for patients on long-term PN (>1 month) in whom there is impaired biliary excretion. The Mn that contaminates PN originates from component solutions. Contamination is highest in solutions of calcium gluconate, magnesium sulfate, sodium chloride, and potassium chloride, but it is present in dextrose and amino acid solutions. In one study, for example, Mn concentrations were $280 \mu \mathrm{g} / \mathrm{L}$ in potassium phosphate and up to $225 \mu \mathrm{g} / \mathrm{L}$ in magnesium sulfate solutions, whereas amino acid solutions contained $5.2-17.0 \mu \mathrm{g} / \mathrm{L}$ and $50 \%$ dextrose contained $0.64-2.5 \mu \mathrm{g} / \mathrm{L}$. ${ }^{65}$ Data on the total Mn contamination of a PN regimen are more useful to the clinician than data on individual components. In the aforementioned study, the total Mn dose delivered by contamination was $8.07-21.75 \mu \mathrm{g} / \mathrm{d}$. Less than $3.3 \mu \mathrm{g}$ of this originated from potassium phosphate and magnesium sulfate because of the 
small volumes of these solutions used. Elsewhere, estimates of total $\mathrm{Mn}$ doses delivered by contamination of $\mathrm{PN}$ regimens range from $3-38 \mu \mathrm{g} / \mathrm{d}^{16,66,67}$

Hypermanganesemia is common in patients treated with long-term PN. At least 50\% of these patients, receiving Mn provision in accordance with the 1979 recommendations, ${ }^{68}$ develop hypermanganesemia, but neurotoxicity is relatively uncommon. $^{31,32,47}$ In 1 study, 11 patients treated with long-term PN all had whole blood Mn concentrations, twice those of controls, as well as positive MRI results, but only 1 patient had parkinsonian-like symptoms. ${ }^{69}$ In a study that investigated 16 patients on long-term PN (receiving Mn doses of $400 \mu \mathrm{g} / \mathrm{d}$ ), 8 had hypermanganesemia, and 13 had positive MRI results, of whom only 2 had parkinsonian-like symptoms. ${ }^{70}$ Whole blood Mn correlates with the dose of Mn and with cerebral accumulation as measured by MRI of the basal ganglia, ${ }^{66,71}$ but it does not reliably predict the development of toxicity in individuals. Serum Mn correlates poorly with accumulation, tending to remain within the reference range despite increased intracerebral Mn concentrations. ${ }^{72}$ It reflects IV delivery rather than $\mathrm{Mn}$ accumulation. It has recently been suggested that $\mathrm{RBC} \mathrm{Mn}$ is preferable to whole blood $\mathrm{Mn}$ as a test of Mn accumulation. ${ }^{37}$ This is to be expected because whole blood is an inhomogeneous mixture of RBCs and plasma, the Mn content of the latter reflecting IV delivery of $\mathrm{Mn}$, whereas RBCs are homogeneous. One study in which supplemental Mn was withheld from patients on long-term PN reported that RBC Mn correlated well with disappearance of cerebral Mn accumulation. ${ }^{30}$ While RBC $\mathrm{Mn}$ has potential as a test of $\mathrm{Mn}$ accumulation, there is currently limited information available on its utility, and its measurement is not widely available in clinical laboratories.

The features of PN-associated Mn neurotoxicity closely resemble those of neurotoxicity resulting from occupational Mn exposure. ${ }^{14}$ The symptoms and brain regions affected are the same, and the route whereby Mn enters the bloodstream bypasses the liver. ${ }^{73}$ Another factor common to both conditions is that it is important to detect Mn accumulation at an early stage, if symptoms are to be avoided. There is more information available on occupational Mn toxicity given that it was described much earlier. During the last 10 years in particular, considerable progress has been made in its understanding. ${ }^{14}$ Some of the findings may be applicable to patients treated with PN. For example, tests used for monitoring workers at risk of Mn exposure may find clinical utility in patients treated with PN. The following section therefore considers recent findings on occupational as well as PN-associated Mn neurotoxicity.

Risk factors for Mn neurotoxicity. It is difficult to predict whether patients will develop toxicity when exposed to Mn because susceptibility varies widely among individuals. However, numerous risk factors have been identified. While not all of these have been demonstrated in studies of PN, all are worthy of mention because they potentially apply to patients treated with PN.
Excessive provision. Toxicity may result from the use of MTE products containing too much Mn. Most reports of toxicity have been in adults receiving Mn doses $>500 \mu \mathrm{g} / \mathrm{d}$ or in children receiving doses $>40 \mu \mathrm{g} / \mathrm{kg} / \mathrm{d} .{ }^{16}$ However, critically ill patients may be susceptible to neurotoxicity at lower doses. A recent report described a 62 year old man, chronically critically ill with acute pancreatitis, who developed parkinsonianlike symptoms after 10 weeks of PN containing Mn doses of $270 \mu \mathrm{g} / \mathrm{d}^{74}$ Most case reports of Mn toxicity in PN have been for patients treated for $>3$ months, suggesting that the cumulative dose is important. ${ }^{47}$ Neurotoxicity has been reported in the context of short-term PN. A 22-year-old woman with acute pancreatitis developed Mn encephalopathy after only 2 weeks of PN. ${ }^{48}$ The patient had hypermanganesemia and Mn accumulation in brain. She recovered, albeit with some residual visual impairment, after supplemental Mn was withheld. Mn toxicity presenting with parkinsonian-like symptoms has recently been reported among individuals abusing IV ephedrine. ${ }^{52}$ This may contain Mn concentrations up to $0.6 \mathrm{~g} / \mathrm{L}$, originating from potassium permanganante. The doses of Mn delivered may be 60-180 mg/d, which greatly exceed those in PN. Given that Mn efflux from the brain is slow, the risk of toxicity would be expected to increase as a result of recent exposure to $\mathrm{Mn}$, irrespective of the source.

Liver disease. When biliary excretion is impaired, Mn tends to accumulate in both liver and brain. Patients with cholestatic liver disease, including PN-associated liver disease (PNALD), should therefore be considered at risk of developing neurotoxicity. ${ }^{69}$ Mn toxicity can occur in patients with chronic liver disease who have not received PN. ${ }^{75}$ The presence of collateral vessels, such as esophageal varices, enables Mn absorbed in the gastrointestinal tract to reach the systemic circulation directly, resulting in hypermanganesemia. ${ }^{76}$ Cerebral accumulation of $\mathrm{Mn}$ in patients with liver disease can be reversed by liver transplant. ${ }^{75,77,78} \mathrm{Mn}$ that accumulates in the liver may be directly hepatotoxic. This is considered in a later section.

Age. Infants are more susceptible than adults to developing hypermanganesemia and accumulation of $\mathrm{Mn}$ because immaturity of regulatory mechanisms results in greater absorption and retention of $\mathrm{Mn}$. Mn uptake into the brain is greater because neuronal barriers are more permeable. ${ }^{79}$ This can lead to permanent brain damage. ${ }^{80}$ In the infant population, hypermanganesemia is associated with poorer neurodevelopment. ${ }^{81}$

Fe deficiency. Fe deficiency in children is associated with hypermanganesemia, ${ }^{82,83}$ accumulation of $\mathrm{Mn}$ in brain, ${ }^{84}$ and neurotoxicity. ${ }^{85}$ These observations are of concern given the high prevalence of Fe deficiency worldwide. The mechanism whereby Fe deficiency predisposes to Mn toxicity has been studied in animals. There is increased intestinal absorption and cerebral uptake of Mn caused by increased activity of transport proteins divalent metal transporter 1 , transferrin receptor, and 
ZIP8, expressed in the gastrointestinal tract and brain. ${ }^{86-89}$ It is unknown whether Fe deficiency influences the risk of $\mathrm{Mn}$ toxicity in patients treated with PN.

Selenium deficiency. Patients who are deficient in selenium (Se) may be more susceptible to Mn toxicity. Conversely, normal Se status may have a protective effect. A recent study of TE concentrations in cord blood suggested that Se protects infants against neurotoxicity resulting from prenatal Mn exposure. ${ }^{90}$ A cord blood Se concentration $\geq 63.1 \mu \mathrm{g} / \mathrm{L}$ appeared to block toxic effects of $\mathrm{Mn}$ on neurodevelopment. The mechanism of this effect is unclear, but Se could counteract the oxidative stress believed to contribute to Mn neurotoxicity. These findings suggest that it is advisable to maintain optimal Se status for infants at risk of Mn neurotoxicity. The authors recommended that Se supplementation should be considered for pregnant women living in regions of low natural Se. It is unknown whether Se deficiency influences the risk of Mn toxicity in patients treated with PN, but it should be noted that $\mathrm{Se}$ doses delivered in PN are commonly below the recommended amounts. ${ }^{91}$

Genetic factors. At least 3 lines of evidence suggest that genetic variation may in part explain the large interindividual differences in susceptibility to Mn neurotoxicity. First, singlenucleotide polymorphisms of genes participating in detoxification of Mn are associated with increased susceptibility to Mn neurotoxicity. ${ }^{92,93}$ These variants were considered likely to predispose to Mn toxicity irrespective of the route of exposure. Second, mutations affecting the parkin gene, which are implicated in juvenile-onset PD, predispose to Mn toxicity. ${ }^{94}$ Third, recessively inherited mutations of SLC30A10 cause familial Mn-induced parkinsonism. ${ }^{95}$ Patients with this disorder have severe inherited hypermanganesemia and develop parkinsonian-like symptoms. Milder defects of these genes potentially render individuals more susceptible to hypermanganesemia in the presence of increased intake. Conversely, genetic factors have been identified that may decrease susceptibility to Mn neurotoxicity. For example, a variant of the gene encoding the Fe-regulatory protein hepcidin is associated with blood Mn concentrations that are 10\% lower than in the general population. ${ }^{96}$ Overexpression of parkin may protect against Mn-induced dopaminergic cell death. ${ }^{97}$ In addition, findings of studies in cellular systems have suggested that Mn has an epigenetic role in neurotoxicity. ${ }^{98} \mathrm{Mn}$ exposure resulted in overexpression of $\alpha$-synuclein, a protein leading to apoptosis, which is known to participate in the development of PD. ${ }^{99,100}$

Management of Mn neurotoxicity. The key therapeutic intervention for Mn intoxication is to remove the patient from exposure. Thereafter, symptoms usually resolve, and brain $\mathrm{Mn}$ concentrations decrease. In a review of cases of Mn toxicity in PN, Dickerson reported that resolution of symptoms may take from 3 days to many months. ${ }^{47}$ Symptoms may fail to resolve completely in some patients. Blood $\mathrm{Mn}$ concentrations decrease but, as observed in 1 study of children receiving PN, may take up to 9 months to return to normal. ${ }^{71}$ Signal intensity of the basal ganglia on MRI has been reported to take up to 5 months to return to normal after Mn was withheld from adults treated with PN..$^{53}$ In this study, whole blood Mn concentrations decreased in parallel with MRI signal intensity.

If symptoms persist, other causes should be excluded. Other treatments may be considered, but there is relatively little information available on treatments other than cessation of exposure. Levodopa is unlikely to be effective. ${ }^{46}$ Similarly, the chelating agent ethylenediaminetetraacetic acid fails to improve symptoms despite increasing urinary $\mathrm{Mn}$, probably because, being water soluble, it has limited access across the blood-brain barrier. ${ }^{13,14}$ However, another chelating agent, para-aminosalicylic acid, shows promise in the treatment of Mn neurotoxicity because its metabolite $\mathrm{N}$-acetyl para-aminosalicylic acid reaches the brain. ${ }^{101}$ Patients may benefit from Fe supplementation. In a recent report of a patient with occupational Mn toxicity treated with chelation therapy, the symptoms improved only after supplementation of $\mathrm{Fe} .{ }^{102} \mathrm{Fe}$ may decrease Mn uptake into the brain by competing with it for transport.

\section{Mn-Induced Hepatotoxicity}

Mn may accumulate in the liver of patients treated with longterm PN. An autopsy study of patients on long-term PN, who had received $\mathrm{Mn}$ doses of $700 \mu \mathrm{g} / \mathrm{d}$, found increased concentrations of $\mathrm{Mn}$ in liver, with the highest concentrations being in patients with liver disease. ${ }^{63}$ The consequences of this accumulation are unclear, but it is implicated in the development of PNALD. A large study compared infants treated with PN containing either high $(50 \mu \mathrm{g} / \mathrm{kg} / \mathrm{d})$ or low $(0.91 \mu \mathrm{g} / \mathrm{kg} / \mathrm{d}) \mathrm{Mn}$ doses. ${ }^{103}$ It found that serum direct bilirubin and whole blood Mn concentrations were significantly higher in the high Mn group. In addition, severe hyperbilirubinemia was more common in this group. Further evidence implicating Mn in PNALD is the finding that, in children with cholestasis and hypermanganesemia, serum bilirubin decreased significantly after $\mathrm{Mn}$ was withheld. ${ }^{49}$

Studies of animals suggest that hepatic Mn accumulation is hepatotoxic. There is evidence, dating back to the 1970s, that infusion of Mn contributes to the development of cholestasis. ${ }^{104-107}$ More recently, administration of Mn followed by bilirubin led to a decrease in bile flow, thought to be caused by changes in permeability at the canalicular membrane. ${ }^{107} \mathrm{Mn}$ increases the activity of HMG CoA reductase and decreases conversion of cholesterol to bile acids, ${ }^{108}$ both of which could lead to an increase in hepatic cholesterol concentrations. Excessive hepatic cholesterol could predispose to cholestasis, either by accumulating in the canalicular membrane or by increasing the formation of biliary sludge. ${ }^{109}$ In a study of animals exposed to excess $\mathrm{Mn}$, there was inhibition of the hepatic enzymes MnSOD and glutathione peroxidase and a decrease in hepatic 
concentrations of glutathione. ${ }^{110}$ There were also histopathologic changes in liver indicative of hepatocellular damage. Taken together, the findings suggested that excess hepatic $\mathrm{Mn}$ caused oxidative damage. The effect of hepatic Mn accumulation in humans merits further investigation. Such studies would be facilitated by the development of techniques capable of measuring hepatic Mn concentrations noninvasively,

\section{New Biomarkers of Mn Exposure}

Presymptomatic neurochemical changes that occur following Mn exposure have been quantitated by magnetic resonance spectroscopy. ${ }^{73,111}$ For example, GABA ( $\gamma$-aminobutyric acid) concentrations doubled in the basal ganglia and thalamus of workers exposed to airborne Mn. Increased thalamic GABA is associated with decreased fine motor performance as assessed by the Purdue pegboard test. ${ }^{112}$ The $\mathrm{Mn}: \mathrm{Fe}$ ratio in $\mathrm{RBCs}^{113}$ and plasma ${ }^{114}$ has been used as a marker of occupational $\mathrm{Mn}$ exposure. It correlates with airborne Mn concentrations and with neurobehavioral changes. The rationale for using this ratio is that, by combining the 2 measurements, the sensitivity of the test is increased. In vivo neutron activation analysis is a sensitive, noninvasive, and portable method, recently developed to quantify $\mathrm{Mn}$ in bone, as a test of past exposure. ${ }^{115}$ It can measure concentrations as low as $0.5 \mathrm{ppm}$. Bone Mn concentrations were significantly higher in occupationally exposed than in nonexposed subjects. ${ }^{116}$ These biomarkers have not yet been studied in patients treated with PN.

\section{Mn Deficiency}

Relatively little is known about Mn deficiency in the context of $\mathrm{PN}$, but information is available from other areas of investigation that is potentially applicable to PN. For the purpose of discussion, Mn deficiency can be considered as either severe, in which there are overt clinical features, or mild, in which the features are nonspecific or observed in epidemiologic studies. Mild deficiency of any micronutrient is more difficult to study because it may not be associated with measurable changes in the blood.

\section{Severe Mn Deficiency}

Severe deficiency of $\mathrm{Mn}$ is rare, probably because requirements are readily met by the amounts normally present in the diet, but it has occurred in individuals consuming diets artificially low in Mn. Subjects consuming a diet containing only $110 \mu \mathrm{g} / \mathrm{d}$ of $\mathrm{Mn}$ for 39 days developed a skin rash and hypocholesterolemia, which responded to Mn supplementation. ${ }^{117}$ Other symptoms of Mn deficiency described in humans are weight loss, decreased growth of nails and hair, and reddening of black hair. ${ }^{118,119}$ Skeletal abnormalities and permanent ataxia have been reported in experimental Mn deficiency in animals. Its metabolic effects include impaired antioxidant defense and decreased lipoprotein metabolism. ${ }^{120,121}$ In studies of rats, decreased serum insulin and insulin-like growth factor I concentrations have been reported. ${ }^{122}$

Nondietary Mn deficiency has severe effects that overlap with those of dietary deficiency. A defect affecting ZIP8 was recently reported that caused urinary $\mathrm{Mn}$ wasting, hypomanganesemia, and impaired galactosyltransferase activity. ${ }^{123}$ The clinical features were short stature, intellectual impairment, developmental delay, and hypotonia. Recessively inherited defects of Mn metalloenzymes result in features comparable to those of dietary deficiency. For example, arginase deficiency results in impaired growth, intellectual impairment, and ataxia, ${ }^{124}$ and glutamine synthase deficiency causes seizures, developmental delay, and hypotonia. ${ }^{125}$ The same systems are potentially adversely affected by partial impairment of $\mathrm{Mn}$ metalloenzymes, resulting from insufficient Mn supply.

\section{Mild Mn Deficiency}

Mild or marginal micronutrient deficiency is a state in which overt features of deficiency are absent but which may nevertheless worsen the clinical outcome-for example, by predisposing to infection or by delaying wound healing. These clinical problems result from suboptimal metabolism, caused by impaired activity of enzymes. Mn metalloenzymes participate in a range of physiologic processes, all of which are potentially compromised by Mn deficiency. Evidence suggesting that Mn deficiency is associated with adverse outcomes is discussed here.

Epidemiologic studies have suggested that dietary deficiency of $\mathrm{Mn}$, sufficient to cause hypomanganesemia, may adversely affect cognitive function and growth. A study of 12-month-old infants found an inverted U-shaped association between whole blood Mn concentration and mental development score, with the lowest scores being in the lowest and highest Mn quintiles. ${ }^{81}$ This finding was consistent with Mn acting as both an essential nutrient and a toxicant. The mechanism whereby Mn deficiency affects neurodevelopment is unknown, but oxidative injury could result from decreased activity of MnSOD. In another study, decreased maternal whole blood Mn was associated with intrauterine growth retardation, ${ }^{126}$ and, more recently, studies have shown an inverted U-shaped association between maternal whole blood Mn and birth weight. ${ }^{127-130}$ In adults, low and high blood $\mathrm{Mn}$ are both associated with decreased cognitive function. ${ }^{131}$ In these study populations, the whole blood Mn concentration appears to be sufficiently sensitive to detect clinically significant Mn deficiency.

Various observations have suggested that deficiency of $\mathrm{Mn}$ contributes to diseases affecting growth and cerebral function. Mn deficiency at birth is implicated in Perthe's disease, a condition associated with avascular necrosis of the head of the femur and disordered growth. Children with this condition have lower blood Mn concentrations. ${ }^{132} \mathrm{Mn}$ deficiency is implicated in increased susceptibility to seizures in patients with epilepsy. ${ }^{120,133,134}$ Whole blood Mn was significantly 
lower in hospitalized patients with epilepsy than in control subjects. ${ }^{135}$ This association could reflect the requirement of the nervous system for Mn metalloenzymes. Another study observed that whole blood Mn concentrations were significantly lower in patients with type 2 diabetes than in control subjects. ${ }^{136}$ The consequences of this are unknown, but it could impair insulin secretion. In addition, by increasing oxidative stress and endothelial dysfunction, it is implicated in the development of atherosclerosis. ${ }^{137}$ Dietary Mn deficiency in animal models has been observed to decrease arginase activity in liver and aorta, thereby increasing synthesis of nitric oxide. ${ }^{138,139} \mathrm{~A}$ similar effect occurring in the brain would be expected to compromise neuroprotection.

\section{Mn Deficiency During PN}

The only reported case of severe Mn deficiency in a patient treated with PN is of a child with short bowel syndrome who developed osteoporosis and weight loss after receiving PN unsupplemented with $\mathrm{Mn} .{ }^{140}$ The osteoporosis was probably caused by lack of bone matrix resulting from deficient glycosyltransferase activity. Severe Mn deficiency has not been reported in adults treated with PN. Mn deficiency, unlike $\mathrm{Cu}$ deficiency, does not appear to occur when supplementation is withheld from PN, possibly because requirements are usually met by the amount of Mn present as a contaminant of PN.

In practice, however, patients from whom supplemental $\mathrm{Mn}$ is withheld usually have cholestasis that, by decreasing Mn excretion, might be expected to protect against deficiency. The risk of Mn deficiency could be higher in noncholestatic patients treated with PN from which Mn is withheld. One study investigated such patients who received Mn doses of only 3-6 $\mathrm{\mu g} / \mathrm{d}$ from contamination of the PN. ${ }^{66}$ While whole blood Mn concentrations were significantly lower in these patients than in patients receiving doses of $55 \mu \mathrm{g} / \mathrm{d}$, none of the unsupplemented patients developed overt features of $\mathrm{Mn}$ deficiency during the 13-16 months of the study. However, this small study was not specifically designed to investigate hypomanganesemia. In addition, neurophysiologic tests and tests of cognitive function were not carried out. Another study of patients on long-term PN reported blood Mn concentrations significantly below the reference range 1 year after supplemental Mn had been withheld. ${ }^{30}$ Significantly decreased blood Mn concentrations were observed in a study of patients undergoing cisplatin chemotherapy for esophageal cancer who received 28 days of PN unsupplemented with $\mathrm{Mn} .{ }^{141}$ Although no adverse effects of hypomanganesemia were reported in these studies, this does not necessarily mean that it is an unimportant finding. For example, it is unknown whether hypomanganesemia would be tolerated well over longer periods than in these studies or among patients receiving lower background doses of $\mathrm{Mn}$ from contamination of PN. While the significance of hypomanganesemia during $\mathrm{PN}$ is uncertain, it appears that it could impair neurodevelopment and weight gain in infants and impair cognitive function in adults. Until more information is available on its effects, hypomanganesemia should be considered potentially harmful.

\section{Practical Considerations}

\section{Mn Contamination of $P N$}

Per a study by Pluhator-Murton et al, the amount of Mn contaminating PN varies significantly among manufacturers and among lots from the same manufacturer.$^{67}$ The former is likely accounted for by differences in methods among manufacturers. Another study by the same authors reported that the concentration of Mn delivered to the patient depends on the temperature and duration of storage of the bag. ${ }^{142} \mathrm{Mn}$ concentrations in bags stored at $20^{\circ} \mathrm{C}$ decreased to a trough, $88 \%$ of the starting concentration, at 36 hours, whereas concentrations decreased to the same trough over a period of 30 days in bags stored at $4^{\circ} \mathrm{C}$. The decrease in concentration could have been caused either by precipitation of $\mathrm{Mn}$ or by its adsorption to the bag. These findings suggest that PN regimens with short storage and short infusion times deliver slightly more $\mathrm{Mn}$ to the patient.

In 1984, it was recommended that levels of contamination be known before supplementing Mn. ${ }^{64}$ Although Mn contamination of PN has been extensively measured since then, there is a need for studies on currently available regimens, especially pediatric ones. ASPEN has recommended that such research be carried out and that total Mn contamination not exceed $40 \mu \mathrm{g} / \mathrm{d}$ in a typical adult PN regimen. ${ }^{91}$ It has been suggested that manufacturers of $\mathrm{PN}$ products state the maximum possible Mn contamination on product labels. ${ }^{16}$ It will be difficult for manufacturers to comply with these recommendations because it will require them to consider the Mn content of numerous component solutions.

\section{Mn Provision in PN}

Between 1979-2014, the standard doses of Mn recommended in adults treated with PN decreased 80 -fold, from $800 \mu \mathrm{g} / \mathrm{d}^{68}$ to $10-50 \mu \mathrm{g} / \mathrm{d},{ }^{143}$ following reports of Mn toxicity and research findings suggesting that requirements were lower than previously thought (Table 1). However, MTE products available in the United States still contain Mn doses in line with the 1979 American Medical Association recommendations. ${ }^{68}$ The current recommendation for adults is based on the observation that, in patients receiving $55 \mu \mathrm{g} / \mathrm{d}$, the whole blood Mn concentration remained stable and within the reference range. ${ }^{66}$ MRI signal intensity of the globus pallidus remained stable but increased in patients receiving doses of $110 \mu \mathrm{g} / \mathrm{d}$, suggesting that doses $>55 \mu \mathrm{g} / \mathrm{d}$ can lead to accumulation. It is likely that the average parenteral $\mathrm{Mn}$ requirement in adults is $<55 \mu \mathrm{g} / \mathrm{d}$ and that the standard recommendation will be decreased following further research. However, doses of $55 \mu \mathrm{g} / \mathrm{d}$ appear to be safe, as long as there are no risk factors for toxicity or 
Table 1. Recommendations on Parenteral Mn Supplementation.

\begin{tabular}{|c|c|c|c|c|}
\hline Specific Group ${ }^{\mathrm{a}}$ & Source & Year & Mn Dose ${ }^{b}$ & Reference \\
\hline \multicolumn{5}{|c|}{ Adults } \\
\hline & NAG-AMA & 1979 & $150-800$ & 68 \\
\hline & AMA & 1984 & $400-800$ & 144 \\
\hline & AMA & 1995 & $10-50$ & 143 \\
\hline & ASPEN & 2004 & $60-100$ & 145 \\
\hline & ESPEN & 2009 & $200-300$ & 146 \\
\hline & ASPEN & 2012 & 55 & 91 \\
\hline & AuSPEN & 2014 & 55 & 147 \\
\hline \multicolumn{5}{|c|}{ Children } \\
\hline Children & NAG-AMA & 1979 & $2-10$ & 68 \\
\hline Preterm neonate & ASCN & 1988 & 1 & 148 \\
\hline Term neonate & $\mathrm{ASCN}$ & 1988 & 1 & 148 \\
\hline Children & $\mathrm{ASCN}$ & 1988 & 1 & 148 \\
\hline Preterm neonates $(<3 \mathrm{~kg})$ & ASPEN & 2004 & 1 & 145 \\
\hline Term neonates $(3-10 \mathrm{~kg})$ & ASPEN & 2004 & 1 & 145 \\
\hline Children (10-40 kg) & ASPEN & 2004 & 1 & 145 \\
\hline Adolescents $(>40 \mathrm{~kg})$ & ASPEN & 2004 & $40-100^{\mathrm{c}}$ & 145 \\
\hline
\end{tabular}

AMA, American Medical Association; ASCN, American Society for Clinical Nutrition; ASPEN, American Society for Parenteral and Enteral Nutrition; AuSPEN, Australian Society for Parenteral and Enteral Nutrition; ESPEN, European Society for Clinical Nutrition and Metabolism; Mn, manganese; NAG-AMA, Nutrition Advisory Group of the American Medical Association.

${ }^{\text {a If applicable. }}$

${ }^{b}$ For adults, $\mu \mathrm{g} / \mathrm{d}$; for children, $\mu \mathrm{g} / \mathrm{kg} / \mathrm{d}$ (unless noted otherwise).

${ }^{\mathrm{c}}$ Value presented as $\mu \mathrm{g} / \mathrm{d}$.

significant intake of $\mathrm{Mn}$ from other sources. Authors have questioned whether patients treated with long-term PN should be routinely supplemented with Mn. ${ }^{12,63,149}$ A recent systematic review concluded that there was limited evidence to support the practice of withholding supplemental Mn for all patients receiving long-term PN. ${ }^{150}$ The authors suggested that further studies were required to assess the safety of this approach.

Individualization of Mn provision. Mn doses, in common with those of other TEs, should ideally be tailored to patients' requirements. While this may not always be feasible, prescribers of PN should certainly be alert to situations in which patients' individual requirements may be below the standard recommendations.

Additional intake. Before deciding on supplementation of PN, clinicians should consider other sources of Mn intake. These include IV infusions, such as electrolytes or blood products, given separately from PN. It is difficult to account for the amounts delivered in this way because there is limited information available on the Mn content of these infusions. Nevertheless, the amounts may be considerable when large volumes are infused. For example, calcium gluconate is given in large volumes to $\mathrm{PN}$-treated preterm infants to prevent osteopenia of prematurity. ${ }^{149}$ There may be additional intake via the oral or enteral routes. Clinicians should be aware that oral Mn supplements are available that deliver doses of $2-4 \mathrm{mg} / \mathrm{d}^{151}$
The value of such supplements is questionable given that $\mathrm{Mn}$ is readily available in most diets and that excessive intake can be harmful. Mn concentrations in drinking water in the United States commonly exceed $300 \mu \mathrm{g} / \mathrm{L} .{ }^{152}$ Excessive consumption of tea resulted in hypermanganesemia in an enterally fed patient. ${ }^{153}$ Previous IV ephedrine abuse should be considered as a possible source of intake. ${ }^{52}$

Cholestasis. Mn provision should be decreased or withheld in patients with significant cholestasis, irrespective of the duration of PN. ${ }^{47,91}$ For neonates, it has been recommended that Mn be withheld if the serum bilirubin concentration exceeds $2 \mathrm{mg} /$ dL. ${ }^{149}$ For adults, Mn should be withheld if aminotransferases and alkaline phosphatase are more than twice normal levels. ${ }^{63}$ However, caution is required when assessing the severity of cholestasis because liver function tests have limited sensitivity. The finding that liver function tests are within normal limits does not rule out the possibility of liver disease sufficiently severe to cause $\mathrm{Mn}$ accumulation. If there is doubt about the severity of cholestasis, withholding supplemental $\mathrm{Mn}$ is unlikely to be harmful. The MTE product should be withheld, and the other TEs, normally provided by the product $(\mathrm{Cu}, \mathrm{Se}$, and $\mathrm{Zn}$ ), should be given as individual TE products, either in the $\mathrm{PN}$ or as a separate infusion.

Critical illness. Limited data are available to guide $\mathrm{Mn}$ provision for the critically ill, but requirements are likely to 
decrease. In 2009 the European Society for Clinical Nutrition and Metabolism recognized that $\mathrm{Mn}$ requirements of critically ill patients were below the amount provided by standard MTE products available at the time $(200-550 \mu \mathrm{g} / \mathrm{d}) .{ }^{154} \mathrm{In}$ a study of trauma patients receiving hemofiltration, the amount of Mn delivered in PN (300 $\mu \mathrm{g} / \mathrm{d})$ exceeded Mn losses, suggesting that there was accumulation. ${ }^{155}$ This study reported that Mn was present as a contaminant of dialysate solutions. The authors concluded that $\mathrm{Mn}$ doses of $60-100 \mu \mathrm{g} / \mathrm{d}$ may exceed the requirements of patients on hemofiltration. Another reason to decrease Mn supplementation in critically ill patients is the additional intake from electrolyte infusions and blood products. In summary, it is advisable to decrease Mn provision in critically ill patients, especially those treated with hemofiltration. Mn supplementation should not exceed $55 \mu \mathrm{g} / \mathrm{d}$.

Hypermanganesemia. Patients with hypermanganesemia should be considered at risk of developing toxicity and their Mn provision reviewed. ASPEN recommends decreasing or withholding $\mathrm{Mn}$ provision in patients with hypermanganesemia. ${ }^{11}$ If it is uncertain whether the hypermanganesemia is genuine or artifactual, the safest approach is to withhold supplementation. Withholding $\mathrm{Mn}$ in the absence of accumulation is unlikely to be harmful, whereas continuing provision in the presence of genuine hypermanganesemia risks toxicity.

Hypomanganesemia. Hypomanganesemia is an unusual metabolic complication in patients treated with PN. It is unlikely to occur in patients whose PN is supplemented with the MTE products currently available, but, as discussed, it can occur when supplemental $\mathrm{Mn}$ is withheld. ${ }^{66}$ Because there is limited information available, it is uncertain what action should be taken, but clinicians should be alert to possible features of Mn deficiency. It is unknown whether these features would resemble those observed in subjects with artificially induced Mn deficiency. ${ }^{48}$ If hypomanganesemia is persistent or accompanied by features consistent with deficiency, the clinician may consider restarting Mn provision. This should be done cautiously, either by restarting the MTE product — adjusting the doses of any single TE product $(\mathrm{Cu}, \mathrm{Se}, \mathrm{Zn})$ as necessaryor by delivering $\mathrm{Mn}$ as an individual TE product. The Mn dose should not exceed $55 \mu \mathrm{g} / \mathrm{d}$, and whole blood Mn should be measured 1 month after restarting supplementation. ${ }^{63}$ Overt features of Mn deficiency might be expected respond promptly to supplementation, given that the skin rash observed in studies of artificially induced $\mathrm{Mn}$ deficiency settled within a few days. ${ }^{117}$ Again, however, it is unknown whether this observation is applicable to patients treated with PN.

MTE products. In practice, decisions on Mn supplementation are constrained, first by the formulation of the MTE product available and second by the availability or otherwise of individual TE products. In 2012 ASPEN reviewed the MTE products available in the United States and Europe. ${ }^{91}$ At the time, the products for use in adults delivered Mn doses of 100-800 $\mu \mathrm{g}$ (United States) and 200-550 $\mu \mathrm{g} / \mathrm{d}$ (Europe). Pediatric products delivered doses of $2-10 \mu \mathrm{g} / \mathrm{kg} / \mathrm{d}$. It was concluded that adult and pediatric products both provided excessive amounts of Mn. Observational studies of patients treated with long-term PN have found evidence of potentially toxic accumulation of Mn resulting from these doses. ${ }^{70,156}$ The ASPEN review recommended that Mn doses in MTE products for use in adults should be decreased to $55 \mu \mathrm{g} / \mathrm{d}$ to match the recommendation on provision and that pediatric and neonatal products should be reformulated to deliver doses of $1 \mu \mathrm{g} / \mathrm{kg} / \mathrm{d}$. These recommendations were reinforced by a recent call to action to bring safer MTE products to the U.S. market. ${ }^{157}$ The publication listed the evidence for actual or potential Mn toxicity resulting from the currently available products. It was hoped that the ASPEN recommendations would encourage commercial companies to develop new MTE products.

In addition to delivering excessive doses of Mn, the currently available MTE products do not facilitate individualization of dosing in patients whose requirements are below the standard recommendation. In this situation, the MTE product can be withheld, and the other TEs can be provided via individual TE products at doses that meet patients' individual requirements for these TEs. However, this approach is not without problems. In countries where individual TE products are unavailable - for example, because of product shortages the options available to the prescriber are either to provide the MTE product, thereby risking Mn toxicity, or to decrease or withhold the product, risking deficiency of $\mathrm{Cu}, \mathrm{Se}$, or $\mathrm{Zn}$. The approach is costly, increases the risk of errors, and is logistically more complex when PN is compounded off-site. There may be a case for developing an Mn-free MTE product to facilitate provision of TEs other than $\mathrm{Mn}$ for patients in whom $\mathrm{Mn}$ is withheld. Ideally, a range of MTE products would be available, containing TE doses appropriate for different, commonly occurring situations.

Since 2012, 2 new MTE products have been developed for use in adults. ${ }^{157}$ Both provide Mn doses of $55 \mu \mathrm{g} / \mathrm{d}$, in line with the ASPEN recommendations. These are a welcome development for patients and prescribers in Europe, but they are not yet available for use in the United States, because they contain Fe, fluoride, iodide, and molybdenum, not contained in the standard products available in the United States. However, it is likely that the currently available U.S. products will be reformulated to bring their Mn content into line with the recommendations. Clinicians intending to prescribe a new MTE product should ensure that it is compatible with the PN regimen of choice.

\section{Monitoring of Mn Status During PN}

Given that Mn accumulation is detectable presymptomatically, it should be possible to prevent toxicity developing. When Mn is withheld from patients with accumulation, the outcome appears to be good in that both hypermanganesemia and 
Table 2. Recommendations on Frequency of Monitoring of Whole Blood Mn.

\begin{tabular}{lcc}
\hline Patient Category & Frequency, mo & Reference \\
\hline Stable adults receiving $55 \mu \mathrm{g} / \mathrm{d}$ of Mn & 12 & 147 \\
Patients in whom Mn was withheld from PN & $6-12$ & 63 \\
Patients receiving high doses of Mn & $3-6$ & $147,158,159$ \\
Infants receiving prolonged PN & 3 & 149,160 \\
Patients with cholestasis (total bilirubin $>3.5 \mathrm{mg} / \mathrm{dL})$ & 1 & 158,161 \\
Chronically critically ill patients receiving $>55 \mu \mathrm{g} / \mathrm{d}$ of Mn & 1 & 48,74 \\
\hline
\end{tabular}

Mn, manganese; PN, parenteral nutrition.

cerebral $\mathrm{Mn}$ accumulation improve and the patient remains asymptomatic. ${ }^{71} \mathrm{Mn}$ status should therefore be monitored in all patients treated with long-term PN. Clinical monitoring should include regular neurologic examination, with the clinician being alert to both parkinsonian-like and nonspecific symptoms of toxicity. ${ }^{47,49} \mathrm{Mn}$ provision should be withheld if toxicity is suspected..$^{91}$ Neurophysiologic tests, such as tests of fine motor coordination, are not routinely carried out but could be used as an adjunct to clinical examination. ${ }^{37,114}$ Biochemical monitoring consists of measuring whole blood Mn and liver function tests. Recommendations on the frequency of Mn measurement are based on expert opinion (Table 2). Essentially, measurements should be more frequent for patients at increased risk of $\mathrm{Mn}$ accumulation. In an effort to avoid artifactual results, specimen tubes should be approved by the local TE laboratory. If artifactual hypermanganesemia is suspected, clinicians should consider rechecking the whole blood Mn concentration both on a specimen collected into a standard tube and on a second specimen collected simultaneously into a TE-free tube. It is advisable to monitor Fe status and, if necessary, correct deficiency.

Currently, there is no consensus on the utility of cerebral MRI in monitoring patients treated with PN. Authors have recommended MRI for monitoring Mn accumulation in patients who have liver dysfunction or are receiving long-term PN. ${ }^{16,162}$ Others have stated that MRI may be appropriate if toxicity is suspected. ${ }^{149,160}$ In my opinion, MRI is appropriate in patients who have neurologic symptoms, the cause of which is uncertain or which fail to resolve after $\mathrm{Mn}$ is withheld. In this situation, MRI may have utility in distinguishing Mn toxicity from other causes. Whether MRI has a place in routine monitoring of asymptomatic patients is more doubtful. It is too costly and impractical. Moreover, the results would be unlikely to influence clinical management because, in patients with hypermanganesemia, Mn is likely to be withheld irrespective of the MRI findings. While increased signal intensity in a normomanganesemic patient could be used as a basis for withholding Mn provision, this situation would be unusual because signal intensity and whole blood Mn correlate strongly. ${ }^{53,66}$ Whole blood Mn is the preferred test and should be considered the mainstay of monitoring. A practical point to note is that use of MRI is precluded when ferrous equipment is being used and for patients who are bedbound. ${ }^{74}$

\section{Mn and Long-Term PN}

It is worth emphasizing some points about the management of patients who are receiving long-term PN because these patients, whether at home or critically ill in the hospital, are at increased risk of developing Mn toxicity. Clinicians should be aware of factors predisposing to Mn toxicity, especially high doses of Mn. Mn intake in fluids, drugs, nutritional supplements, and PN should be assessed. At present, there is limited information available on Mn doses delivered in fluids and drugs, but it is likely that, in the future, pharmaceutical companies will make more information of this sort routinely available. It is important to be alert to the possibility of cholestasis and PNALD and to remember that when standard liver function tests are within reference limits, this does not rule out susceptibility to toxicity. Whole blood Mn should be monitored at least annually among stable patients and more frequently if there are risk factors for toxicity. If a patient has symptoms consistent with Mn toxicity, blood Mn should be measured promptly, MRI considered, and supplemental Mn withheld. In this event, I recommend monitoring blood Mn monthly thereafter until it returns to normal. Other risk factors for Mn toxicity, including Se and Fe deficiency, should be treated. A specialist neurologic opinion should be sought and other causes of parkinsonian-like symptoms, such as PD or drugs, ruled out.

Mn deficiency could occur if supplemental Mn has been withheld long-term, although the risk thereof would appear to be low. While hypomanganesemia has been observed when supplemental Mn has been withheld, it is uncertain whether this indicates that the patient is at increased risk of developing features of deficiency. However, clinicians should monitor patients for overt deficiency, keeping in mind that this would not necessarily present with features, such as hair discoloration, as described in the studies of artificially induced Mn deficiency, but could conceivably present with nonspecific features, such as cognitive dysfunction, poor wound healing, or susceptibility to infection. In addition, whole blood Mn should be monitored at least annually among patients with hypomanganesemia. The finding of normomanganesemia in a patient with features consistent with Mn deficiency should suggest the possibility of an artifactual increase resulting from specimen contamination. In this situation, it would be appropriate to repeat the measurement on a blood specimen collected into a 
TE-free tube. Current evidence does not support routinely withholding Mn long-term for patients who do not have risk factors for toxicity.

\section{Future Directions}

There is a need for new tests, such as genetic tests, to be developed to help identify patients at risk of Mn toxicity. It is likely that advances will be made in imaging techniques, enabling cerebral and hepatic Mn accumulation to be detected presymptomatically. Neurophysiologic tests show promise as a means of detecting neurotoxic features at an early stage. $\mathrm{RBC} \mathrm{Mn}$ merits further investigation as a test of $\mathrm{Mn}$ accumulation.

Pharmaceutical companies should consider developing Mn-free MTE products to simplify TE prescribing in patients with cholestasis or hypermanganesemia. Prescribers would welcome information on Mn contamination of PN regimens and IV fluids given in large volumes to critically ill patients. In time, purification methods may be developed, which will decrease or even eliminate Mn contamination. It is hoped that new MTE products, which provide Mn in line with the 2012 ASPEN recommendations, will soon be widely used in clinical practice. This would be expected to decrease the incidence of Mn toxicity. In this event, it would be appropriate for recommendations on monitoring of $\mathrm{Mn}$ to be reviewed. Future research into $\mathrm{Mn}$ requirements may lead to a further decrease in recommended Mn provision, and as standard provision moves closer to average requirements, Mn deficiency may increase in incidence, ultimately becoming a commoner concern than toxicity. Future research should study hypomanganesemia and its consequences in patients treated with PN.

\section{Statement of Authorship}

C. Livingstone contributed to the conception/design of the research; contributed to the acquisition, analysis, or interpretation of the data; drafted the manuscript and critically revised it; agrees to be fully accountable for ensuring the integrity and accuracy of the work; and read and approved the final version.

\section{References}

1. Hurley LS, Keen CL. Manganese. In: Mertz W, ed. Trace Elements in Human and Animal Nutrition. Orlando, FL: Academic Press; 1987: 185-223.

2. Emsley J. Manganese. In: Nature's Building Blocks: An A-Z Guide to the Elements. Oxford, UK: Oxford University Press; 2001:249-253.

3. Rahil-Khazen R, Bolann BJ, Myking A, Ulvik RJ. Multi-element analysis of trace element levels in human autopsy tissues by using inductively coupled atomic emission spectrometry technique (ICP-AES). J Trace Elem Med Biol. 2002;16:15-25.

4. Gunter TE, Miller LM, Gavin CE, et al. Determination of the oxidation states of manganese in brain, liver and heart mitochondria. J Neurochem. 2004;88:266-280.

5. Korc M. Manganese action on pancreatic protein synthesis in normal and diabetic rats. Am J Physiol. 1983;245:G628-G634.

6. Hiney JK, Srivastava VK, Dees WL. Manganese induces IGF-I and cyclooxygenase-2 gene expression in the basal hypothalamus during prepubertal female development. Toxicol Sci. 2011;121:389-396.
7. Palacios C. The role of nutrients in bone health, from A to Z. Crit Rev Food Sci Nutr. 2006;46:621-628.

8. Agency for Toxic Substances and Disease Registry. Toxicological Profile for Manganese. Atlanta, GA: Agency for Toxic Substances and Disease Registry; 2000.

9. Lonnerdal B. Nutritional aspects of soy formula. Acta Paediatr Suppl. 1994;402:105-108.

10. U.S. Environmental Protection Agency. Drinking Water Health Advisory for Manganese. Washington, DC: U.S. Environmental Protection Agency; 2004.

11. Aschner JL, Aschner M. Nutritional aspects of manganese homeostasis. Mol Asp Med. 2005;26:353-362.

12. Hardy IJ, Gillanders L, Hardy G. Is manganese an essential supplement for parenteral nutrition? Curr Opin Clin Nutr Metab Care. 2008;11: 289-296.

13. Cossgrove J, Zheng W. Manganese toxicity upon overexposure. $N M R$ Biomed. 2004;17:544-553.

14. O'Neal SL, Zheng W. Manganese toxicity upon overexposure: a decade in review. Curr Environ Health Rep. 2015;2:315-328.

15. Missiaen L, Raeymaekers L, Dode L, et al. SPCA1 pumps and HaileyHailey disease. Biochem Biophys Res Commun. 2004;322:1204-1213.

16. Hardy G. Manganese in parenteral nutrition: who, when and why should we supplement? Gastroenterol. 2009;137:S29-S35.

17. Finley JW. Manganese absorption and retention by young women is associated with serum ferritin concentration. Am J Clin Nutr. 1999;70:37-43.

18. Malecki EA, Devenyi AG, Barron TE, et al. Iron and manganese homeostasis in chronic liver disease: relationship to pallidal T1-weighted magnetic resonance signal hyperintensity. Neurotoxicol. 1999;20:647-652.

19. Horning KJ, Caito SW, Tipps KG, Bowman AB, Aschner M. Manganese is essential for neuronal health. Annu Rev Nutr. 2015;35:71-108.

20. Estevez AG, Sahawneh MA, Lange PS, Bae N, Egea M, Ratan RR. Arginase 1 regulation of nitric oxide production is key to survival of trophic factor-deprived motor neurons. J Neurosci. 2006;26:8512-8516.

21. Takeda A. Manganese action and brain function. Brain Res Rev. 2003;41:79-87.

22. Zou J, Wang YX, Dou FF, et al. Glutamine-synthetase down regulation reduces astrocyte protection against glutamate excitotoxicity to neurons. Neurochem Int. 2010;56:577-584.

23. Buettner GR, Ng CF, Wang M, Rodgers JGJ, Schafer FQ. A new paradigm: manganese superoxide dismutase influences the production of $\mathrm{H} 2 \mathrm{O} 2$ in cells and thereby their biological state. Free Rad Biol Med. 2006;41:1338-1350.

24. Yokel RA, Crossgrove JS, Bukaveckas BL. Manganese distribution across the blood-brain barrier II: manganese efflux from the brain does not appear to be carrier mediated. Neurotoxicol. 2003;24:15-22.

25. Tan J, Zhang T, Jiang L, et al. Regulation of intracellular manganese homeostasis by Kufor-Rakeb syndrome-associated ATP13A2 protein. $J$ Biol Chem. 2011;286:29654-29662.

26. Zhang S, Fu J, Zhou Z. Changes in the brain mitochondrial proteome of male Sprague-Dawley rats treated with manganese chlolride. Toxicol Applied Pharmacol. 2005;202:13-17.

27. Kobayashi K, Kuroda J, Shibata N, et al. Induction of metallothionein by manganese is completely dependendt on interleukin-6. J Pharmacol Exp Ther. 2007;320:721-727.

28. Erikson K, Aschner M. Manganese causes differential regulation of glutamate transporter (GLAST) taurine transporter and metallothionein in cultured rat astrocytes. Neurotoxicology. 2002;23:595-602.

29. Mehta R, Reilly JJ. Manganese levels in a jaundiced long term parenteral nutrition patient. JPEN J Parenter Enteral Nutr. 1990;14:428-430.

30. Bertinet DB, Tinivella M, Balzola FA, et al. Brain manganese deposition and blood levels in patients undergoing home parenteral nutrition. JPEN J Parenter Enteral Nutr. 2000;24:223-227.

31. Wardle CA, Forbes A, Roberts NB, Jawhari AV, Shenkin A. Hypermanganesaemia in long-term intravenous nutrition and chronic liver disease. JPEN J Parenter Enteral Nutr. 1999;23;350-355. 
32. Fitzgerald K, Mikalunas V, Rubin H, McCarthy R, Vanagunas A, Craig RM. Hypermanganesaemia in patients receiving total parenteral nutrition. JPEN J Parenter Enteral Nutr. 1999;23:333-336.

33. Spencer A. Whole blood manganese levels in pregnancy and the neonate. Nutrition. 1999;15:731-734.

34. Metzer HM, Brant Saeter AL, Borch-Iohnsen B, et al. Low iron stores are related to higher blood concentrations of manganese, cobalt and cadmium in non-smoking, Norwegian women in the HUNT 2 study. Environ Res. 2010;110:497-504.

35. Pleban PA, Pearson KH. Determination of manganese in whole blood and serum. Clin Chem. 1979;25:1915-1918.

36. Cesbron A, Saussereau E, Mahieu L, Couland I, Guerbet M, Goulle JP. Metallic profile of whole blood and plasma in a series of 106 healthy volunteers. J Anal Toxicol. 2013;37:401-405.

37. Santos D, Batoreu C, Mateus L, Marreilha Dos, Santos AP, Aschner M. Manganese in human parenteral nutrition: considerations for toxicity and biomonitoring. Neurotoxicology. 2014;43:36-45.

38. McMillan NB, Mulroy C, MacKay MW, McDonald CM, Jackson WD. Correlation of cholestasis with serum copper and whole blood manganese levels in paediatric patients. Nutr Clin Pract. 2008;23:161-165.

39. Malecki EA, Lo HC, Yang H, Davis CD, Ney DM, Greger JL. Tissue manganese concentrations and antioxidant enzyme activities in rats given total parenteral nutrition with and without supplemental manganese. JPEN J Parenter Enteral Nutr. 1995;19:222-226.

40. Greger JL. Dietary standards for manganese: overlap between nutritional and toxicological studies. J Nutr. 1998;128:368S-371S.

41. Hallgren R, Feltelius N, Lindh U. Redistribution of minerals and trace elements in chronic inflammation - a study on isolated blood cells from patients with ankylosing spondylitis. J Rheumatol. 1987;14:548-553.

42. Versieck J, Barbier F, Speecke A, Hoste J. Manganese, copper, and zinc concentrations in serum packed blood cells during acute hepatitis, chronic hepatitis, and posthepatitic cirrhosis. Clin Chem. 1974;20:1141-1145.

43. Couper J. On the effects of black oxide of manganese when inhaled into the lungs. Br Ann Med Pharm Vital Stat Gen Sci. 1837;1:41-42.

44. Li G, Zhang L, Lu L, Wu P, Zheng W. Occupational exposure to welding fume among welders: alterations of manganese, iron, zinc, copper and lead in body fluids and the oxidative stress status. J Occup Environ Med. 2004;46:241-248.

45. Lu L, Zhang LL, Li GJ, Guo W, Liang W, Zheng W. Alteration of serum concentrations of manganese, iron, ferritin and transferrin receptor following exposure to welding fumes among career welders. Neurotoxicology. 2005;26:257-265.

46. Kwakye GF, Paoliello MMB, Mukhopadhyay S, Bowman AB, Aschner M. Manganese-induced Parkinsonism and Parkinson's disease: shared and distinguishable features. Int J Environ Res Public Health. 2015;12:7519-7540.

47. Dickerson RN. Manganese intoxication and parenteral nutrition. Nutrition. 2001;17:689-693.

48. Chalela JA, Bonillha L, Neyens R, Hays A. Manganese encephalopathy: an under recognised condition in the intensive care unit. Neurocrit Care. 2011;14:456-458.

49. Fell JM, Reynolds AP, Meadows N, et al. Manganese toxicity in children receiving long term parenteral nutrition. Lancet. 1996;347:1218-1221.

50. Calne DB, Chu NS, Huang CC, Lu CS, Olanow W. Manganism and idiopathic Parkinsonism: similarities and differences. Neurology. 1994;44:1583-1586.

51. Jiang YM, Zheng W, Long LL, et al. Brain magnetic resonance imaging and manganese concentrations in red blood cells of smelting workers: search for biomarkers of manganese exposure. Neurotoxicology. 2007;28:126-135.

52. Sikk K, Haldre S, Aquilonius SM, Taba P. Manganese induced Parkinsonism due to ephedrine abuse. Parkinsons Dis. 2011;2011:865319.

53. Takagi Y, Okada A, Sando K, Wasa M, Yoshida H, Hirabuki N. On-off study of manganese administration to adult patients undergoing home parenteral nutrition: new indices of in vivo manganese level. JPEN $J$ Parenter Enteral Nutr. 2001;25:87-92.
54. Verity MA. Manganese neurotoxicity: a mechanistic hypothesis. Neurotoxicology. 1999;20:489-497.

55. Watts RJ, Sarasa J, Loge FJ, Teel AL. Oxidative and reductive pathways in manganese-catalyzed Fentons reactions. J Environ Eng. 2005;131: 158-164.

56. Zwingmann C, Leibfritz D, Hazell AS. Brain energy metabolism in a subacute rat model of manganese neurotoxicity: an ex vivo nuclear magnetic resonance study using [1-13C] glucose. Neurotoxicology. 2004;25:573-587.

57. Hazell AS, Normandin L, Norenberg MD, Kennedy G, Yi JH. Alzheimer type II astrocytic changes following subacute exposure to manganese and its prevention by antioxidant treatment. Neurosci Lett. 2005;396:167-171.

58. Morello M, Zatta P, Zambenedetti P, et al. Manganese intoxication decreases the expression of manganoproteins in the rat basal ganglia: an immunohistochemical study. Brain Res Bull. 2007;74:406-415.

59. Hazell AS, Norenberg MD. Manganese decreases glutamate uptake in cultured astrocytes. Neurochem Res. 1997;22:1443-1447.

60. Elima A, Imamura T, Nakamura S, Saito H, Matsumoto K, Momono S. Manganese intoxication during total parenteral nutrition. Lancet. 1992;339:426.

61. Ono J, Harada K, Kodaka R, et al. Manganese deposition in the brain during long-term total parenteral nutrition. JPEN J Parenter Enteral Nutr. 1995;19:310-312.

62. Mirowitz SA, Westrich TJ, Hirsch JD. Hyperintense basal ganglia on T1-weighted MR images in patients receiving parenteral nutrition. Radiology. 1991;181:117-120.

63. Howard L, Ashley C, Lyon D, Shenkin A. Autopsy tissue trace elements in eight long term parenteral nutrition patients who received the current US FDA formulation. JPEN J Parenter Enteral Nutr. 2007;31:388-396.

64. Leach RM. Manganese in enteral and parenteral nutrition. Bull N Y Acad Med. 1984;60:172-176.

65. Kurkus J, Alcock NW, Shils ME. Manganese content of large-volume parenteral solutions and of nutrient additives. JPEN J Parenter Enteral Nutr. 1984;8:254-257.

66. Takagi Y, Okada A, Sando K, Wasa M, Yoshida H, Hirabuki N. Evaluation of indexes of in vivo manganese status and the optimal intravenous dose for adult patients undergoing home parenteral nutrition. $\mathrm{Am}$ J Clin Nutr. 2002;75:112-118.

67. Pluhator-Murton MM, Fedorak RN, Audette RJ, Marriage BJ, Yatscoff RW, Gramlich LM. Trace element contamination of total parenteral nutrition: 1. Contribution of component solutions. JPEN J Parenter Enteral Nutr. 1999;23:222-227.

68. AMA Department of Foods and Nutrition. Guidelines for essential trace element preparations for parenteral use: a statement by an expert panel. JAMA. 1979;241:2051-2054.

69. Reimund JM, Dietemann JL, Warter JM, Baumann R, Duclos B. Factors associated to hypermanganesaemia in patients receiving home parenteral nutrition. Clin Nutr. 2000;19:343-348.

70. Abdalian R, Saqui O, Fernandes G, Allard JP. Effects of manganese from a commercial multi-trace element supplement in a population sample of Canadian patients on long-term parenteral nutrition. JPEN J Parenter Enteral Nutr. 2013;37:538-543.

71. Kafritsa Y, Fell J, Long S, Bynevelt M, Taylor W, Milla P. Long term outcomes of brain manganese deposition in patients on home parenteral nutrition. Arch Dis Child. 1998;79:263-265.

72. Alves G, Thiebot J, Tracqui A, Delangre T, Guedon C, Lerebours E. Neurologic disorders due to brain manganese deposition in a jaundiced patient receiving long-term parenteral nutrition. JPEN J Parenter Enteral Nutr. 1997;21:41-45.

73. Jiang YM, Zheng W, Long LL, et al. Brain magnetic resonance imaging and manganese concentrations in red blood cells of smelting workers: search for biomarkers of manganese exposure. Neuro Toxicol. 2007;28:126-135.

74. Walter E, Alsaffar S, Livingstone C, Ashley SL. Manganese toxicity in critical care: case report, literature review and recommendations for practice. J Int Care Soc. 2015;17. 
75. Klos KJ, Ahlskog JE, Josephs KA, et al. Neurologic spectrum of chronic liver failure and basal ganglia $\mathrm{T} 1$ hyperintensity on magnetic resonance imaging: probable manganese neurotoxicity. Arch Neurol. 2005;62:1385-1390.

76. Spahr L, Butterworth RF, Fontaine S, et al. Increased blood manganese in cirrhotic patients: relationiship to pallidal magnetic resonance signal hyperintensity and neurological symptoms. Hepatology. 1996;24:1116-1120.

77. Uchino A, Noguchi T, Nomiyama K, et al. Manganese accumulation in the brain: MR imaging. Neuroradiology. 2007;49:715-720.

78. Long LL, Li XR, Huang ZK, Jian YM, Fu SX, Zheng W. Relationship between changes in brain MRI and 1H-MRS, severity of chronic liver damage and recovery after liver transplantation. Expo Med Biol. 2009;234:1075-1085.

79. Michalke B, Fernsebner K. New insights into manganese toxicity and speciation. J Trace Elem Med Biol. 2014;28:106-116.

80. Erikson KM, Thompson K, Ashner J, Ashner M. Manganese neurotoxicity: a focus on the neonate. Pharmacol Ther. 2007;113:369-377.

81. Claus Henn B, Ettinger AS, Schwartz J, et al. Early postnatal blood manganese levels and children's neurodevelopment. Epidemiology. 2010;21:433-439

82. Park S, Sim CS, Lee H, Kim Y. Blood manganese concentration is elevated in infants with iron deficiency. Biol Trace Elem Res. 2013;155:184-189.

83. Rahman MA, Rahman B, Ahmed N. High blood manganese in irondeficient children in Karachi. Public Health Nutr. 2013:16:1677-1683.

84. Roth JA, Garrick MD. Iron interactions and other biological reactions mediating the physiological and toxic actions of manganese. Biochem Pharmacol. 2003;66:1-13.

85. Brna P, Gordon K, Dooley JM, Price V. Manganese toxicity in a child with iron deficiency and polycythemia. J Child Neurol. 2010;26:891-894.

86. Heilig EA, Molina R, Donaghey T, Brain JD, Wessling-Resnick M. Pharmacokinetics of pulmonary manganese absorption: evidence for increased susceptibility to manganese loading in iron deficient rats. $A m ~ J$ Physiol Lung Cell Mol Physiol. 2005;288:887-893.

87. Aschner M, Dorman DC. Mangansese: pharmacokinetics and molecular mechanisms of brain uptake. Toxicol Rev. 2006;25:147-154.

88. Kim J, Li Y, Buckett PD, et al. Iron-responsive olfactory uptake of manganese improves motor function deficits associated with iron deficiency. PLoS One. 2012;7:e33533.

89. Kelleher T, Ryan E, Barrett S, et al. Increased DMT1 but not IREG1 or HFE mRNA following iron depletion therapy in hereditary haemochromatosis. Gut. 2004;1174-1179.

90. Yang X, Bao Y, Fu H, Li L, Ren T, Yu X. Selenium protects neonates against neurotoxicity from prenatal exposure to manganese. PloS One. 2014;9:e86611.

91. Vanek VW, Borum P, Buchman A, et al. ASPEN position paper: recommendations for changes in commercially available parenteral multi-vitamin and multi-trace element products. Nutr Clin Pract. 2012;27:440-491.

92. Kim LA, Cheong HK, Joo KD. Effect of manganese exposure to the neuroendocrine system in welders. Neuro Toxicol. 2007;28:263-269.

93. Zheng YX, Chan P, Pan ZF, et al. Polymorphism of metabolic genes and susceptibility to occupational chronic manganism. Biomarkers. 2002;7:337-346.

94. Roth JA, Ganapathy B, Ghio AJ. Manganese-induced toxicity in normal and human B lymphocyte cell lines containing a homozygous mutation in parkin. Toxicol In Vitro. 2012;26:1143-1149.

95. Leyva-Illades D, Chen P, Zogzas CE, et al. SLC30A10 is a cell surface-localized manganese efflux transporter, and parkinsonism-causing mutations block its intracellular trafficking and efflux activity. $J$ Neurosci. 2014;34:14079-14095.

96. Claus Henn B, Kim J, Wessling-Resnick M, et al. Associations of iron metabolism genes with blood manganese levels: a population-based study with validaton data from animal models. Environ Health. 2011;10. Article 97.

97. Higashi Y, Asanuma M, Miyazaki I, Hattori N, Mizuno Y, Ogawa N. Parkin attenuates manganese-induced dopaminergic cell death. $J$ Neurochem. 2014;89:1490-1497.
98. Tarale P, Chakrabarti T, Sivanesan S, Naoghare P, Bafana A, Krishnamurthi K. Potential role of epigenetic mechanism in manganese induced neurotoxicity. BioMed Res Int. 2016;2016:2548792.

99. Li Y, Sun L, Cai T, et al. Alpha-synuclein overexpression during manganese-induced apoptosis in SH-SY5Y neuroblastoma cells. Brain Res Bull. 2010;81:428-433.

100. Covey JP, Giasson BI. Alpha-synuclein, leucine-rich repeat kinase-2 and manganese in the pathogenesis of Parkinson disease. Neuro Toxicol. 2011;32:622-629.

101. Jiang YM, Mo XA, Du FQ, et al. Effective treatment of manganeseinduced occupational parkinsonism with PAS-Na: a case of 17 year follow-up study. J Occup Environ Med. 2006;48:644-649.

102. Tuschl K, Mills PB, Clayton PT. Manganese and the brain. Int Rev Neurobiol. 2013;110:277-312.

103. Fok TF, Chui KK, Cheung R, Ng PC, Cheung KL, Hjelm M. Manganese intake and cholestatic jaundice in neonates receiving parenteral nutrition: a randomized controlled study. Acta Pediatr. 2001;90:1009-1015.

104. Plaa GL, de Lamirande E, Lewittes M, Yousef IM. Liver cell plasma membrane lipids in manganese bilirubin-induced intrahepatic cholestasis. Biochem Pharmacol. 1982;31:3698-3701.

105. Singh J, Husain R, Tandon SK, Seth PK, Chandra SV. Biochemical and histopathological alterations in early manganese toxicity in rats. Environ Physiol Biochem. 1974;4:16-23.

106. Ayotte P, Plaa GL. Hepatic subcellular distribution of manganese in manganese- and manganese-bilirubin-induced cholestasis. Biochem Pharmacol. 1985;34:3857-3865.

107. Dahlstrom-King L, Couture J, Plaa GL. Functional changes of the biliary tree associated with experimentally-induced cholestasis: sulfobromophthalein on manganese-bilirubin combinations. Toxicol App Pharmacol. 1991;108:559-567.

108. Akoume MY, Perwaiz S, Yousef IM, Plaa GL. Synergistic role of 3-hydroxy-3-methylglutaryl coenzyme A reductase and cholesterol7-alpha-hydroxylase in the pathogenesis of manganese-bilirubin induced cholestasis in rats. Toxicol Sci. 2003;73:378-385.

109. Goering PL. The road to elucidating the mechanism of manganese-bilirubin-induced cholestasis. Toxicol Sci. 2003;73:216-219.

110. Huang P, Li G, Chen C, et al. Differential toxicity of $\mathrm{Mn}^{2+}$ and $\mathrm{Mn}^{3+}$ to rat liver tissues: oxidative damage, membrane fluidity and histopathological changes. Exp Toxicol Pathol. 2012:64:197-203.

111. Dydak U, Jiang YM, Long LL, et al. In vivo measurement of brain GABA concentrations by magnetic resonance spectroscopy in smelters occupationally exposed to manganese. Environ J Health Perspect. 2011;2:219-224.

112. Long $\mathrm{Z}, \mathrm{Li} \mathrm{XR}, \mathrm{Xu} \mathrm{J}$, et al. Thalamic GABA predicts fine motor performance in manganese-exposed smelter workers. PLoS One. 2014;9:e88220.

113. Cowan DM, Fan Q, Zou Y, et al. Manganese exposure among smelting workers: blood manganese-iron ratio as a novel tool for manganese exposure assessment. Biomarkers. 2009;14:3-16.

114. Cowan DM, Zheng W, Zou Y, et al. Manganese exposure among smelting workers: relationship between blood manganese-iron ratio and early onset neurobehavioural alterations. Neurotoxicology. 2009;30: 1214-1222.

115. Liu Y, Byrne P, Wang H, Koltick D, Zheng W, Nie LH. A compact DD neutron generator-based NAA system to quantify manganese (Mn) in bone in vivo. Physiol Meas. 2014;35:1899-1911.

116. Pejovic-Milic A, Aslam Chettel DR, Oudyk J, Pysklywec MW, Haines $\mathrm{T}$. Bone manganese as a biomarker of manganese exposure: a feasibility study. Am J Ind Med. 2009;52:742-750.

117. Friedman BJ, Freeland-Graves JH, Bales CW, et al. Manganese balance and clinical observations in young men fed a manganese deficient diet. $J$ Nutr. 1987;117:133-143.

118. Levander OA. Selenium, chromium and manganese. In: Shils ME, Young VR eds. Modern Nutrition in Health and Disease. 7th ed. Philadelphia, PA: Lea \& Febiger; 1988:274. 
119. Freeland-Graves JH, Turnlund JR. Deliberations and evaluations of the approaches, endpoints and paradigms for manganese and molybdenum dietary recommendations. J Nutr. 1996;126:2435S-2440S.

120. Aschner M. Manganese: brain transport and emerging research needs. Environ Health Perspect. 2000;108(suppl 3):429-432.

121. Keen CL, Enunsa JL, Watson MH, et al. Nutritional aspects of manganese from experimental studies. Neurotoxicology. 1999;20:213-223.

122. Clegg MS, Donovan SM, Monaco MH, Baly DL, Ensunsa JL, Keen CL. The influence of manganese deficiency on serum IGF-I and IGF binding proteins in the male rat. Proc Soc Exp Biol Med. 1998;219:41-47.

123. Boycott KM, Beaulieu CL, Kernohan KD, et al. Autosomal recessive intellectual disability with cerebellar atrophy syndrome caused by mutation of the manganese and zinc transporter gene SLC39A8. Am J Hum Gen. 2015;97:886-893.

124. Morris SM. Arginases and arginine deficiency syndromes. Curr Opin Clin Nutr Metab Care. 2012;15:64-70.

125. Haberle J, Gorg B, Toutain A, et al. Inborn error of amino acid synthesis: human glutamine synthetase deficiency. $J$ Inherit Metab Dis. 2006;29:352-358.

126. Vigeh M, Yokoyama K, Ramezanzadeh F, et al. Blood manganese levels and intrauterine growth restriction. Reprod Toxicol. 2008;25:219-223.

127. Zota AR, Ettinger AS, Bouchard M, et al. Maternal blood manganese levels and infant birth weight. Epidemiology. 2009;20:367-373.

128. Eum JH, Cheong HK, Ha EH, et al. Maternal blood manganese level and birth weight: a MOCEH birth cohort study. Environ Health. 2014;13:31.

129. Guan H, Wang M, Li X, et al. Manganese concentrations in maternal and umbilical cord blood: related to birth size and environmental factors. Eur J Public Health. 2014;24:150-157.

130. Chen L, Ding G, Gao Y, et al. Manganese concentrations in maternalinfant blood and birth weight. Environ Sci Pollut Res Int. 2014;21: 6170-6175.

131. Santos-Burgoa C, Rios C, Mercado LA, et al. Exposure to manganese: health effects on the general population, a pilot study in central Mexico. Environ Res. 2001;85:90-104.

132. Hall AJ, Margetts BM, Barker DJ, et al. Low blood manganese in Liverpool children with Perthe's disease. Paediatr Perinat Epidemiol. 1989;3:131-135.

133. Samsel A, Seneff S. Glyphosate, pathways to modern diseases III: manganese, neurological diseases and associated pathologies. Surg Neurol Int. 2015;6:45

134. Papavasilious PS, Kutt H, Miller ST, Rosal V, Wang YY, Aronson RB. Seizure disorders and trace metals: manganese tissue levels in treated epileptics. Neurology. 1979;29:1466-1473.

135. Carl GF, Keen CL, Gallagher BB, et al. Association of low blood manganese concentrations with epilepsy. Neurology. 1986;36:1584-1587.

136. Kazi TG, Afridi HI, Kazi N, et al. Copper, chromium, manganese, iron, nickel and zinc levels in biological samples of diabetes mellitus patients. Biol Trace Elem Res. 2008;122:1-18.

137. Burlet E, Jain SK. Manganese supplementation reduces high glucoseinduced monocyte adhesion to endothelial cells and endothelial dysfunction in Zucker diabetic fatty rats. J Biol Chem. 2013;288:6409-6416.

138. Brock AA, Chapman SA, Ulaman EA, Wu G. Dietary manganese deficiencydecreases rat hepatic arginase activity. J Nutr. 1993;124:340-344.

139. Ensunsa JL, Symons JD, Lanoue L, Schrader HR, Keen CL. Reducing arginase activity via dietary manganese deficiency enhances endotheliumdependent vasorelaxation in rat aorta. Exp Biol Med. 2004;229:1143-1153.

140. Norose N, Terai M, Norose K. Manganese deficiency in a child with very short bowel syndrome receiving long term parenteral nutrition. J Trace Elem Exp Med. 1992;5:100-101.

141. Akutsu Y, Kono T, Uesato M, et al. Are additional trace elements necessary in total parenteral nutrition for patients with esophageal cancer receiving cisplatin-based chemotherapy? Biol Trace Elem Res. 2012;150:109-115.

142. Pluhator-Murton MM, Fedorak RN, Audette RJ, Marriage BJ, Yatscoff RW, Gramlich LM. Trace element contamination of total parenteral nutrition: 2. Effect of storage duration and temperature. JPEN J Parenter Enteral Nutr. 1999;23:228-232.

143. American Medical Association. Electrolytes, minerals and trace elements: recommended daily intravenous intake during TPN. In: Drug Evaluations Annual. Milwaukee, WI: American Medical Association, 1995:2311-2312.

144. Shils ME, White PL. Working conference on parenteral trace elements: sponsored by NY Acad Med and AMA. Bull N Y Acad Med. 1984;60:115-212

145. Mirtallo J, Canada T, Johnson D, et al. Safe practices for parenteral nutrition. JPEN J Parenter Enteral Nutr. 2004;28:S39-S70.

146. Braga M, Ljungqvist O, Soeters P, Fearon K, Weimann K, Bozzetti F. ESPEN guidelines on parenteral nutrition: surgery. Clin Nutr. 2009;28:378-386

147. Osland EJ, Ali A, Isenring E, Ball P, Davis M, Gillanders L. Australasian Society for Parenteral and Enteral Nutrition guidelines for supplementation of trace elements during parenteral nutrition. Asia Pac J Clin Nutr. 2014;23:545-554.

148. Greene HL, Hambidge M, Schanler R, Tsang R. Guidelines for the use of vitamins, trace elements, calcium, magnesium and phosphorus in infants and children receiving total parenteral nutrition: report of the Subcommittee on Pediatric Parenteral Nutrient Requirements from the Committee on Clinical Practice Issues of the American Society for Clinical Nutrition. Am J Clin Nutr. 1988;48:1324-1342.

149. Burjonrappa SC, Miller M. Role of trace elements in parenteral nutrition support of the surgical neonate. J Ped Surg. 2012;47:760-771.

150. Baker B, Ali A, Isenring L. Recommendations for manganese supplementation to adult patients receiving long-term home parenteral nutrition: an analysis of the supporting evidence. Nutr Clin Pract. 2016;31:180-185.

151. Price CT, Langford JR, Liporace FA. Essential nutrients for bone health and a review of their availability in the average North American diet. Open Orthop J. 2012;6:143-149

152. DeSimon LA, Hamilton PA, Gilliom RJ. The Quality of Our Nation's Waters: Quality of Water From Domestic Wells in Principal Aquifers of the United States, 1991-2004-Overview of Major Findings. Washington, DC: U.S. Department of the Interior; 2009. National WaterQuality Assessment Program circular 1332.

153. Ross C, O'Reilly DS, McKee R. Potentially clinically toxic concentrations of whole blood manganese in a patient fed enterally with a high tea consumption. Ann Clin Biochem. 2006;43:226-228.

154. Singer P, Berger MM, Van den Berghe G, et al. ESPEN guidelines on parenteral nutrition: intensive care. Clin Nutr. 2009;28:387-400.

155. Klein CJ, Nielsen FH, Moser-Veillon PB. Trace element loss in urine following traumatic injury. JPEN J Parenter Enteral Nutr. 2008;32:129-139.

156. Btaiche IF, Carver PL, Welch KB. Dosing and monitoring of trace elements in long-term home parenteral nutrition patients. JPEN J Parenter Enteral Nutr. 2011;35:736-747.

157. Vanek VW, Borum P, Buchman A, et al. A call to bring safer parenteral micronutrients products to the U.S. market. Nutr Clin Pract. 2015;30:559-569

158. NICE. Nutrition Support in Adults: Oral Nutrition Support, Enteral Tube Feeding and Parenteral Nutrition. London, UK: NICE; 2006. NICE clinical guideline 32 .

159. Fessler TA. Trace element monitoring and therapy for adult patients receiving long-term total parenteral nutrition. Pract Gastroenterol. 2005;29(3):44-65.

160. Ono J, Harada K, Kodaka R, et al. Manganese deposition in the brain during long term total parenteral nutrition. JPEN J Parenter Enteral Nutr. 1995;19:310-312.

161. Fessler TA. Trace elements in parenteral nutrition: a practical guide for dosage and monitoring for adult patients. Nutr Clin Pract. 2013;28: 722-729.

162. Stehle P, Stoffel-Wagner B, Kuhn KS. Parenteral trace element provision: recent clinical research and practical considerations. Eur J Clin Nutr. 2016;70(8):886-893. 